\title{
Telemedicine: An Era Yet to Flourish in India
}

\author{
Shilpa Sharma \\ Department of Pediatric Surgery, \\ All India Institute of Medical Sciences, New Delhi.
}

With the rapid expansion of internet facilities, there is already a growing tendency amongst the lay men and the patients to gather information about their symptoms, diagnosis, investigations, medicines, diseases and prognosis. Hence it is but natural that the health care professionals around the world have become very careful of the information they are providing online with each hospital trying to dissipate disease related information through its official websites. Advances in telecommunications technology has paved the way for telemedicine.

Telemedicine is described as a provision of remote clinical services, via real-time twoway communication between the patient and the healthcare provider, using electronic audio and visual means. It is a subset of telehealth that refers to wholesome concept of more general health services; a collection of means or methods for enhancing health care, public health, and health education delivery and support using telecommunications technology.

Today, phone calls, video calls, live video telemedicine, smart phones, computers and smart televisions with a network of internet access are available even in remote areas of the country. Telemedicine has already taken a place in people's lives. A simple phone call from a patient to seek a doctor's advice about a non emergency ailment is a form of telemedicine. Telemedicine usually employs a desktop computer, with a special video card. The computer stores data securely. High-speed telephone lines or satellite connections allow interaction between two sites or locations. On occasions, the patient is at the originating site, and receives the service via telecommunications service, with the mediation of a telepresenter.

\section{Types of Telemedicine-based on Connections}

\section{Networked Programs}

These use networked connections with high speed internet to link remote health clinics to larger health facilities like tertiary level hospitals.

\section{Point-to-point Connections}

These link small, understaffed remote health centers to specialists at one, large, central health facility via high speed internet. These are popular in the developed counres; telepsychiatry, teleradiology and emergency services.

\section{Monitoring Center Links}

These are used for remote patient monitoring. This link creates a digital connection between a patient's house and a remote monitoring facility, so that a patient's medical data can be measured at home and transmitted electronically to a distant medical monitoring facility. These links may be in the form of internet, short message service (SMS), or telephone connections. They are most commonly used for monitoring of pulmonary, cardiac, or fetal medical data. Electrocardiogram data is easily transferred using these links. 
Types of Telemedicine-based on Data or Information Transferred

\section{Store-and-forward Telemedicine Solutions}

They are asynchronous meaning that the specialist, patient, and primary doctor does not need to be communicating at the same time. They enable the primary doctor to forward and share patient medical data like laboratory results, images, videos, records with a specialist at a different location in a sophisticated and secure way. The best use is in the field of teleradiology that allow technicians and healthcare professionals at smaller hospitals to share patient x-rays for diagnosis by a specialist at another location. Other fields include teledermatology, teleophthalmology and pathology.

\section{Remote Patient Monitoring or Telemonitoring or Home Telehealth}

These allow healthcare providers to track a patient's vital signs and other health data from a distance. They felicitate recognition of warning signs that need intervention. They are useful chronic diseases like diabetes; hypertension and also post operative follow- up.

\section{Real-time Interactive Services or Real-time Telehealth}

They are synchronous and involve a live audio-video interaction between either a health professional and patient, or between health professionals. It provides a virtual alternative to a physical visit with the use of a compatible device, internet connection, microphone, and webcam.

Telemedicine is a technology that may have both advantages and few disadvantages. Fortunately the advantages as given in Table 1 outnumber the disadvantages outlined in Table 2. as follows:

Few popular telemedicine specialties are

\section{Teleradiology}

This was one of the earliest specialities of telemedicine to begin way back in 1947 when images were transmitted via phone lines (1). It was developed to expand the access to read xrays. Smaller hospitals that may not always have a radiologist on staff or all the time can send a patient's X-rays and records securely to a qualified radiologist at another location, and get a quick opinion.

\section{Telepsychiatry}

Qualified psychiatrists can provide treatment to patients remotely, expanding access to behavioral health services (2).

\section{Teledermatology}

These are usually store-and-forward

\section{Table 1: Advantages of telemedicine}

\begin{tabular}{|l|l|}
\hline 1. & Convenient to the patient; obviates physical visit to clinic or hospital. \\
\hline 2. & Cost-effective; saves time and money \\
\hline 3. & $\begin{array}{l}\text { Follow-up of patients with chronic diseases such as diabetes, high cholesterol, or high } \\
\text { blood pressure can be easily done. }\end{array}$ \\
\hline 4. & $\begin{array}{l}\text { Advice can be sought for dose adjustment of medications, lifestyle regimens, } \\
\text { prescription reordered or get an access to a support group. }\end{array}$ \\
\hline 5. & Help the doctor select urgent calls after clinic timings \\
\hline 6. & Easier for a busy physician to help out more patients \\
\hline
\end{tabular}




\begin{tabular}{|c|c|}
\hline 7. & $\begin{array}{l}\text { Patients are using technology to monitor their vitals, blood sugar, blood pressure and } \\
\text { hence would be more compliant in monitoring if they have to report their status to the } \\
\text { physician. }\end{array}$ \\
\hline 8. & $\begin{array}{l}\text { Especially useful for International patients to seek the best available expertise } \\
\text { worldwide. }\end{array}$ \\
\hline 9. & $\begin{array}{l}\text { Comfortable approach for those who feel daunted by medical professionals and } \\
\text { hospitals. }\end{array}$ \\
\hline 10. & $\begin{array}{l}\text { As the medical information is exchanged in strict confidence this can also encourage a } \\
\text { good relationship to develop between patients and healthcare professionals. }\end{array}$ \\
\hline 11. & $\begin{array}{l}\text { Telemedicine can be applied in places such as rural, remote, post disaster communities } \\
\text { where there is no constant healthcare available or the necessary transport facilities. }\end{array}$ \\
\hline 12. & $\begin{array}{l}\text { This can be an effective tool in health education by allowing the observation and } \\
\text { supervision of newly-qualified healthcare professionals during clinical practice. } \\
\text { Teaching files can also be made available in many forms, (e.g. Web casts of lectures, } \\
\text { daily presentations of cases, educational conferences) whilst eliminating the necessity } \\
\text { for travel. }\end{array}$ \\
\hline 13. & $\begin{array}{l}\text { Elderly patient with mobility issues restraining to visit a doctor or hospital may be seen } \\
\text { from home. }\end{array}$ \\
\hline 14. & One can get immediate access to a number of specialists. \\
\hline 15. & $\begin{array}{l}\text { It can provide second opinions easily and faster thus making the patient and physician } \\
\text { experience better. }\end{array}$ \\
\hline 16. & $\begin{array}{l}\text { One can get access to renowned specialists in fields like rare cancers without } \\
\text { restrictions of geographical location. }\end{array}$ \\
\hline 17. & $\begin{array}{l}\text { Small remote hospitals without adequate radiology specialist on-staff can outsource } \\
\text { evaluation of x-rays via telemedicine. }\end{array}$ \\
\hline 18. & $\begin{array}{l}\text { It helps to increase patient engagement by allowing them to connect with their doctor } \\
\text { more frequently, in a convenient way leading to a stronger doctor-patient relationship. }\end{array}$ \\
\hline 19. & Better quality patient care with improved health outcomes are provided. \\
\hline 20. & $\begin{array}{l}\text { Telemedicine adds a dimension of clinical protection for users by eliminating the } \\
\text { possibility of transmitting infectious diseases between healthcare professionals and } \\
\text { patients. }\end{array}$ \\
\hline 21. & $\begin{array}{l}\text { Telemedicine facilitates effective monitoring and treatment thereby reducing the } \\
\text { number of unnecessary outpatient visits }\end{array}$ \\
\hline 22. & $\begin{array}{l}\text { Computerised medical databases allow health professionals in primary care to access } \\
\text { patient records in hospital databases. It also allows mobile collaboration between } \\
\text { healthcare professionals from multiple locations when cases are particularly critical or } \\
\text { might require multidisciplinary approach. }\end{array}$ \\
\hline 23. & $\begin{array}{l}\text { The availability of patient records online has the potential to make patient prescriptions } \\
\text { more reliable and accurate. }\end{array}$ \\
\hline
\end{tabular}




\section{Table 2: Disadvantages of telemedicine}

\begin{tabular}{|l|l|}
\hline 1. & $\begin{array}{l}\text { Subtle unrecognized signs which the doctor may pick up on close clinical } \\
\text { inspection; palpating or auscultation may be missed. }\end{array}$ \\
\hline 2. & Paying the due private doctors fees may be a problem \\
\hline 3. & It may be strenuous for a busy physician if the calls are not scheduled \\
\hline 4. & Requires some training and equipment purchasing \\
\hline 5. & May reduce in-person interactions with doctors \\
\hline 6. & Some telemedicine models may reduce care continuity \\
\hline
\end{tabular}

technologies that allow a local healthcare provider to send a patient picture of a rash or another skin lesion for remote diagnosis and get opinion whether further examination is needed from a dermatologist.

\section{Teleophthalmology}

These allow opthalmologists to examine the patients' eyes and also follow-up the effects of the treatment advice from a distance. These solutions are usually either live or store-andforward telemedicine.

\section{Telenephrology}

These are most commonly used interprofessionally, when a family physician needs to consult a nephrologist about a patient with kidney disease. Patients with renal failure can also benefit from telemedicine by discussing the daily requirement for dialysis treatments on home dialysis with video link supervision.

\section{Teleoncology}

This is a rapidly growing field as more molecular tests and international consultations are being sought. These may use store-andforward tools to forward images for diagnosis and also live video platforms to allow patient to consult with the oncologist.

\section{Telepathlogy}

These allow pathologists to share slides and findings at a distance for diagnosis, research, and education. Most telepathology tools are store-and-forward solutions, allowing pathologists to share and forward highresolution images and videos.

\section{Telerehabilitation}

These allow medical professionals to deliver rehab services (such as physical therapy) remotely.

\section{Telesurgery}

A surgeon may follow up his patients during the post operative period and also later (3).

\section{Telepediatric Surgery}

These allow a pediatric surgeon to give opinion on patients in remote areas (4). A good surgical follow-up may also be maintained with good outcome and better patient -doctor satisfaction $(5,6)$.

\section{Teleobstetrics and Telegynecology}

Allows obstetricians to provide prenatal care to remote areas. Antenatal fetal ultrasound and heart may be monitored. A gynecologist might use a live telemedicine solution to provide birth control counselling.

\section{Teleendocrinology}

An endocrinologist may do live video chats with patients to discuss recent laboratory results and give advice. 


\section{Telepediatrics}

These have been found useful to monitor cardiac care (7). They may be used to give information on vaccination to primary health centres.

\section{Teleneuropsychology}

Neuropsychological consultation and assessment can be done over the phone with patients for suspected cognitive disorders. Standard evaluation techniques are implemented to assess the patient via video technology.

\section{Telenursing}

This utilizes communicative technology to provide remote nursing services. Consultations can be made over the phone to reach a diagnosis and monitor health conditions and symptoms.

\section{Telefamily Medicine}

Can be used to monitor chronic health ailments. High-tech sensors, health and activity monitors, touch-screen technology and websites are used daily to record patient vitals, heart patterns, blood pressure and glucose levels. Readings are logged into personal health records, and alerts are sent wirelessly to healthcare providers when readings fall beyond their normal range.

\section{Telesomnology}

It can be used to monitor nocturnal disorders like deprivation or sleep apnea. Via telemed devices, one can monitor both investigatory and direct treatment. The communicative nature of this technology can provide reports on sleep patterns, body positions and breathing to polish data and metrics and refine treatment courses for patients.

\section{Telerobotic Surgery}

Robotic surgery has been made possible by the tele-systems; Da Vinci (Intuitive), ZEUS
(Computer Motion) and AESOP (Automated endoscope system for optimal positioning) (8). Robotic procedures have been shown to be quicker, have reduced complications and a shorter hospital stay than either the open or laparoscopic techniques while maintaining good cancer control in cancer of the prostate (9).

\section{Telemedicine Clinical Guidelines}

The American Telemedicine Association has put together comprehensive guidelines for a range of specialties based on a survey of over 600 studies, for professionals using telemedicine in primary and urgent care (10). They have recommended some basic protocols and rules when starting a telemedicine program are as follows:-

1. Set-up the right space for telemedicine visits

2. Create a contingency plan for emergencies and referrals

3. Patient Management and Evaluation

4. Quality Assurance

5. Billing

6. In general, follow the same standards as inperson medical services

To conclude, though face-to-face doctor patient visits are valuable and necessary in many circumstances, with growing technology the importance of supplementary telemedicine cannot be undermined. There is tremendous scope and optimism in the use of telemedicine worldwide that is becoming easier and more widely accepted.

The global telemedicine market is worth in billions. This technology has paved the way for innovations like smart Google Glasses and smart watches that can monitor patients' health data and transmit them in real time to health professionals. To keep up with this pace of progress in technology telemedicine will need to overcome all cost issues, administrative barriers, and pave the way for better primary health care in rural India in times to come. 


\section{References}

1. Bashshur RL, Krupinski EA, Thrall JH, Bashshur N (2016). The empirical foundations of teleradiology and related applications: a review of the evidence. Telemed J E Health 22: 868-898.

2. Deslich S, Stec B, Tomblin S, Coustasse A (2013). Telepsychiatry in the $21^{\text {st }}$ century: transforming healthcare with technology. Perspect Health Inf Manag 10: (Summer) If.

3. Asiri A, AlBishi S, AlMadani W, et al (2018). The use of telemedicine in surgical care: a systematic review. Acta Inform Med 26: 201-206.

4. Miller GG, Levesque K (2002). Telehealth provides effective pediatric surgery care to remote locations. J Pediatr Surg 37: 752-754.

5. Postuma R, Loewen L (2005). Telepediatric surgery: capturing clinical outcomes. $J$ Pediatr Surg 40: 813-818.

6. Shivji S, Metcalfe P, Khan A, Bratu I (2011). Pediatric surgery telehealth: patient and clinician satisfaction. Pediatr Surg Intl 27: 523-526.

7. Lopez-Magallon AJ, Otero AV, Welchering $\mathrm{N}$, et al (2015). Patient Outcomes of an International Telepediatric Cardiac Critical Care Program. Telemed $J$ E Health 21: 601-610.

8. Challacombe B, Dasgupta P (2003). Telemedicine- the future of surgery. J Surg 1: 15-17.

9. Menon M(2003). Robotic radical retropubic prostatectomy. Br J Urol Intl 91: 175-176.

10. Practice Guidelines for Telemedicine. http://www.americantelemed.org/home. 